
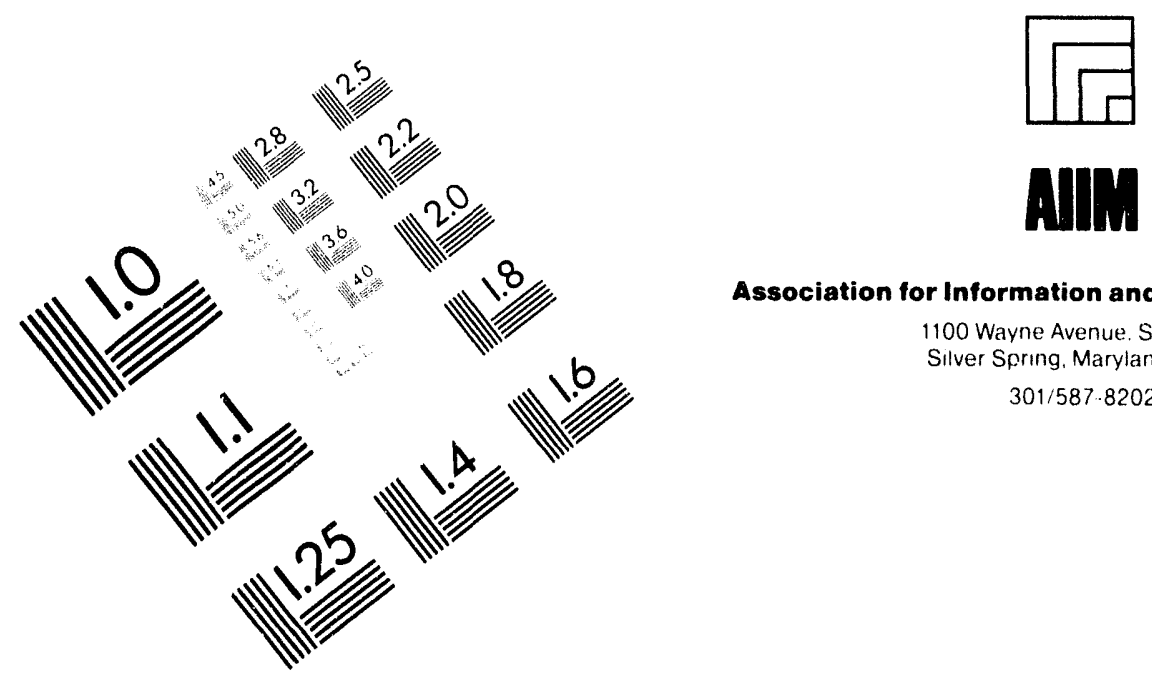

Association for Information and Image Management

1100 Wayne Avenue. Sute 1100

Silver Spring. Maryland 20910

$301 / 587.8202$

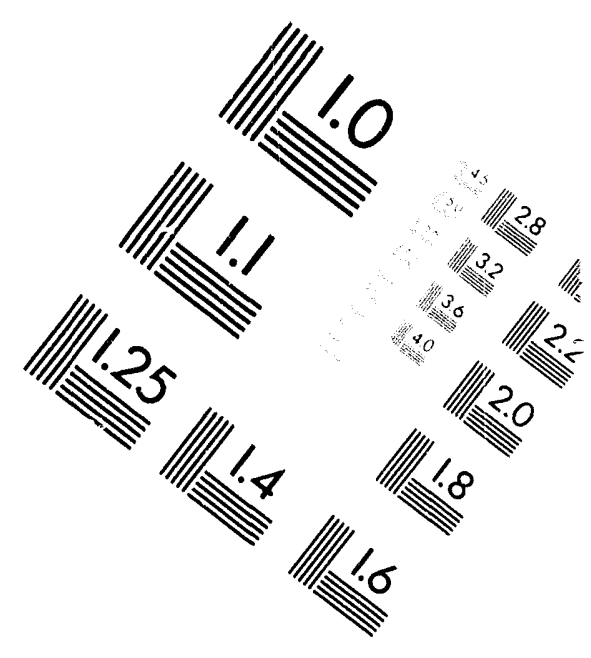

Centimeter

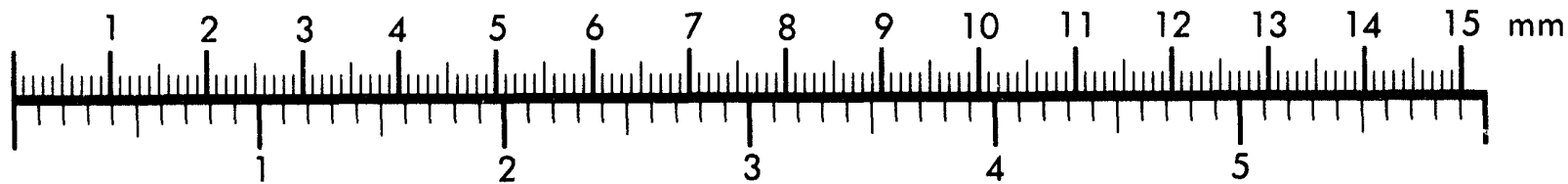

Inches

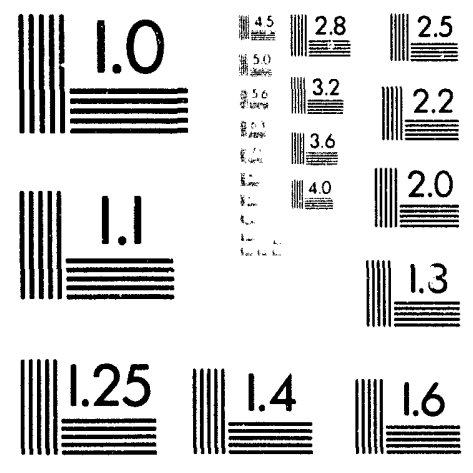

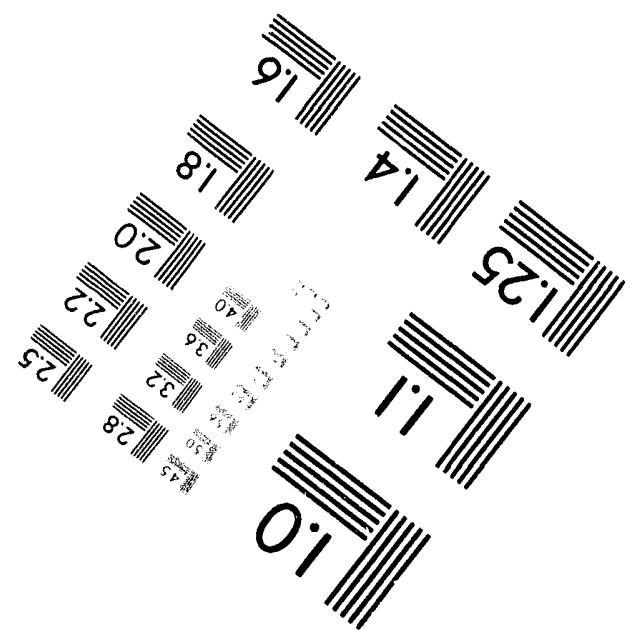

MANUFACTURED TO AIIM STANDARDS

BY APPLIED IMAGE, INC.

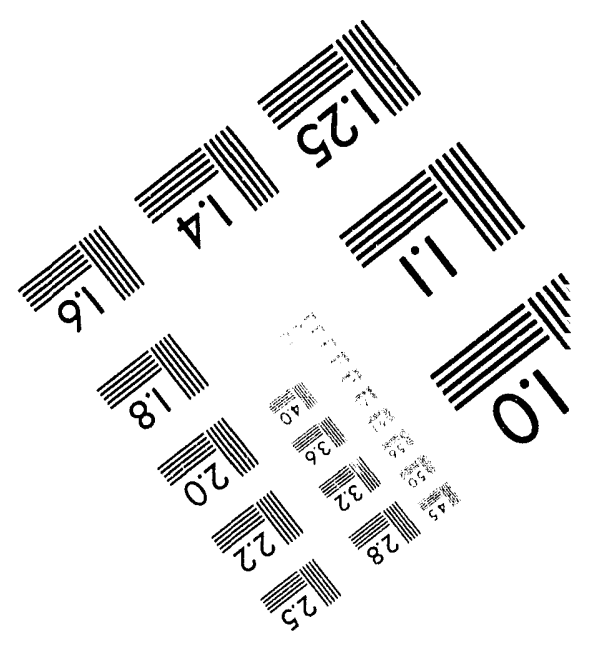



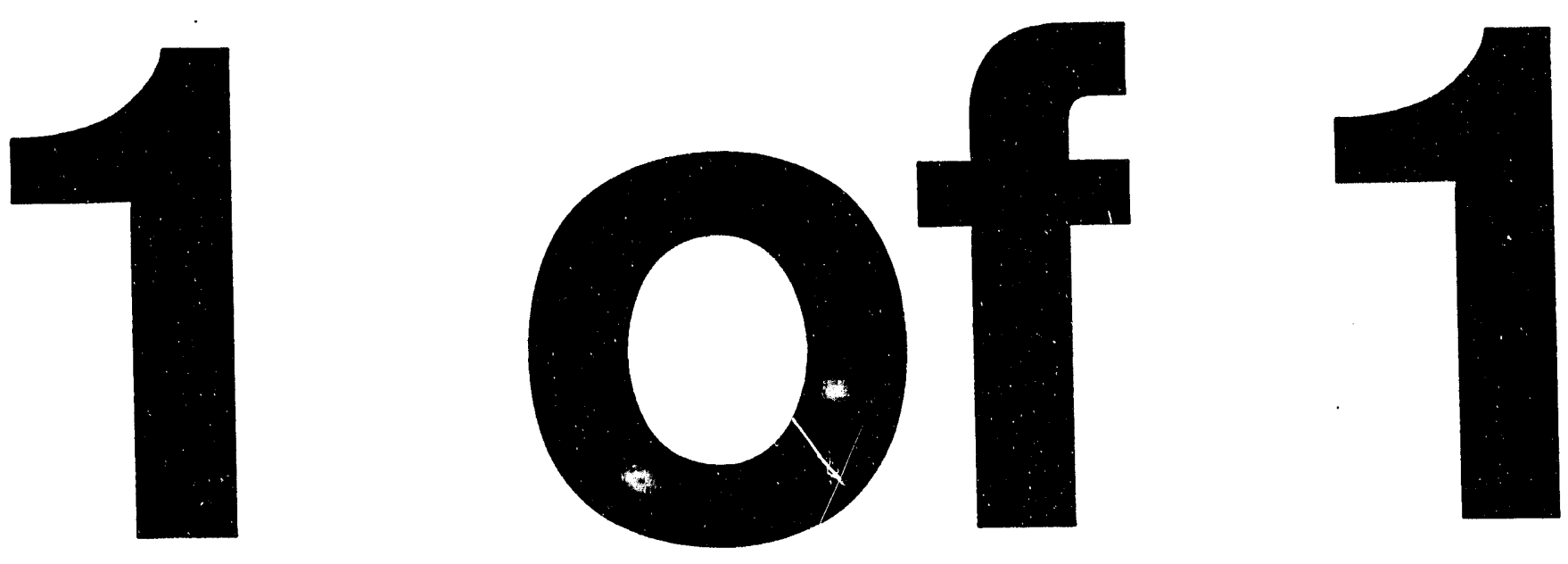
WSRC-TR-94-029

\title{
Electron Beam Technology Demonstration at the Savannah River Site ${ }^{(U)}$
}

\author{
Ahmet Suer
}

May 10, 1994

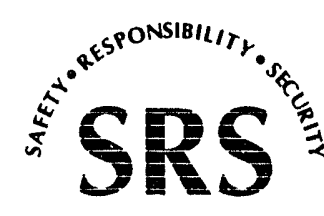




\section{DISCLAIMER}

This repor was prepared as an account of work sponsored by an agency of the United States Government. Neither the United States Government nor any agency thereof, nor any of their employees, makes any warranty, express or implied, or assumes any legal liability or responsibility for the accurary, completeness, or usefulness of any information, apparatus, product, or process disclosed, or represents that its use would not infringe privately owned rights. Reference herein to any specific commercial product, process, or service by trade name, trademark, manufacturer, or otherwise does not necessarily constitute or imply its endorsement, recommendation, or favoring by the United States Government or any agency thereof. The views and opinions of authors expressed herein do not necessarily state or reflect those of the United. States Government or any agency thereof.

This report has been reproduced directly from the best available copy.

Available to DOE and DOE contractors from the Office of Scientific and Technical Information. P. O. Box 62, Oak Ridge. TN 37831; prices available from (615) $576-8401$.

Available to the public from the National Technical Information Service, U. S. Department of Commerce, 5285 Port Royal Rd., Springfield, VA 22161 


\section{Table of Contents}

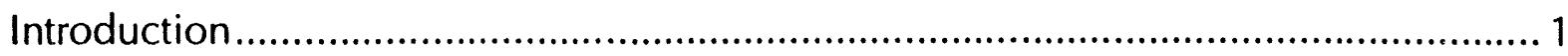

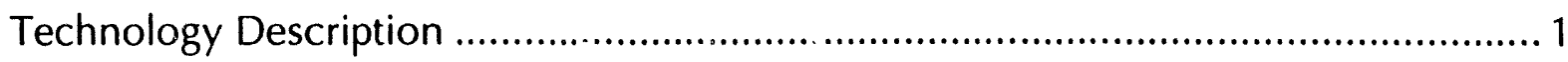

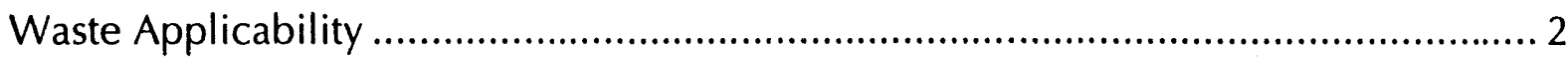

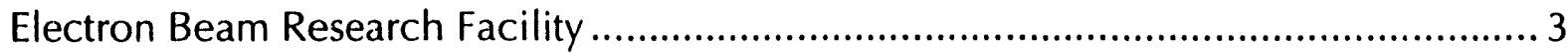

U.S. EPA SITE Program ............................................................................ 4

U.S. EPA SITE Emerging Technology Demonstration of E-Beam .............................. 5

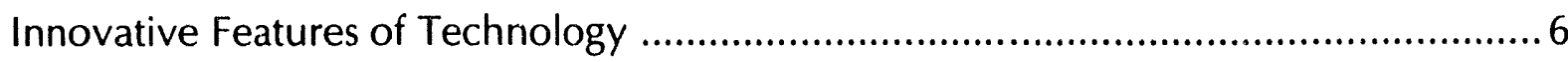

Application and Benefits to SRS .............................................................. 6

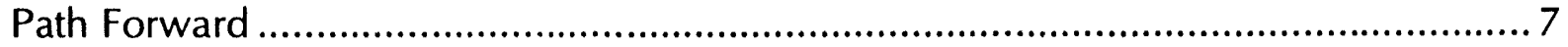

Key Contacts ....................................................................................... 8

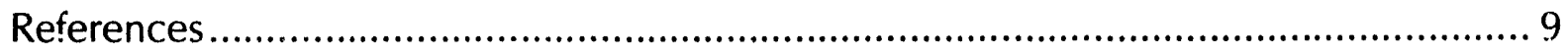

Attachment 1

Figures 


\section{Introduction}

The Department of Energy Environmental Restoration (DOE-ER), Environmental Protection Agency (EPA), and the Westinghouse Savannah River Company (WSRC) Environmental Restoration Department (ER) will jointly demonstrate the electron beam technology at the Savannah River Site (SRS).

The electron beam technology demonstration wiil be performed under the EPA Superfund Innovative Technology Evaluation (SITE) program which is administered by the Risk Reduction Engineering Laboratory (RREL).

\section{Technology Description}

Electron Beam Technology has been in commercial use since the 1950. Applications include sterilization of medical supplies, rubber vulcanization, disinfection of wastewater, food preservation, curing of coating, etc.

Electron beam processing involves exposing the material to be irradiated to a stream of high energy electrons. These electrons interact with the material in less than $10^{-12}$ seconds to produce electrons of lower and lower energy. Eventually a large number of slow electrons with energies less than $50 \mathrm{eV}$ is produced and these electrons interact with molecules to produce excited states of these molecules, positive ions and electrons. Eventually the electrons slo'w to thermal energies and get trapped. In materials of low dielectric constant most electrons do not escape the pull of the positive ions causing a chemical reaction. This is termed direct radiolysis. In high dielectric materials such as water and aqueous solutions, most electrons escape the pull thus leaving both the positive ions and electron free to react with the water or waste components in it. This is referred to as indirect radiolysis. Since the ratio of direct to indirect radiolysis of a waste is approximately the weight fraction of waste to water the radiolysis of water is the primary mechanism of destruction using high energy electrons.

High energy electrons for industrial applications are generally produced by electron accelerators. In these machines a current is used to produce a stream of electrons which are accelerated by applying an electric field generated at a given voltage. The applied voltage determines the speed and thus the energy of the accelerated electrons. For example, an applied voltage of 2.0 MV will accelerate electrons to an energy level of 2.0 $\mathrm{MeV}$. The number of electrons generated per unit time is proportional to the beam current and thus the beam power given by the product of current and voltage. The amount of energy from the high energy beam that is absorbed by an irradiated material per unit mass is called dose. A common unit of dose is the rad, defined as the energy absorption of 100 ergs per gram of material. The amount of energy transferred to the irradiated material is not constant as the electron penetrate deeper into the material. The absorbed dose depends on the type and thickness of the material, the beam power, and the length of time the material is exposed to the electron beam. 
Irradiation of aqueous solutions with high-energy electrons results in the formation of the aqueous electron, hydrogen radical, $\mathrm{H}$; and the hydroxyl radical, $\mathrm{OH}$,. These reactive transient species initiate chemical reactions capable of destroying organic compounds in aqueous solution, in most cases oxidizing them to carbon dioxide, water, and salt. No sludge is formed and no pretreatment is necessary. The reaction by-products are non-toxic and thus process represents a new technology for the restoration of contaminated water, soils, and sediment. ${ }^{\prime}$

A conceptual diagram of the electron beam technology is shown in Figure 1.

\section{Waste Applicability}

This process has demonstrated the ability to treat complex mixtures of hazardous chemicals in the drinking water, groundwater and wastewater, sludge, and water containing up to $5 \% \mathrm{w} / \mathrm{w}$ suspended solids. According to the SITE program, electron beam technology is effective in removing the following compounds:

- chloroform

- benzene

- bromodicholoromethane

- toluene

- dibromochloromethane

- phenol

- bromoform

- zylene

- 1,1,1-tricholoroethane

- chlorobenzene

- 1,1,2,2-tetrachloroethane

- dichlorobenzene

- carbon tetrachloride

- nitrobenzene

- TCE

- ethylbenzene

- PCE

- 4-nitrophenol

- trans-1,2-dichloroethene

- dieldrin

- cis-1,2-dichloroethene

- dimethylmethylphosphonate

- 1,1-dicholoroethene

- acetone

- hexachloro-1,3-butadiene

- glyoxal

- hexachloroethane

- acetaldehyde

- methylene chloride

- acetic acid

- o-cresol

- formic acid 


\section{The Electron Beam Research Facility}

The Electron Beam Research Facility (EBRF) is located at the Miami-Dade Central water District wastewater treatment Plant located on Virginia Key, Miami, Florida. Schematic diagrams of the ERBF are shown in Figure 2. This facility consists of a horizontal transformer (ICT) type, capable of delivering up to $60 \mathrm{~mA}$ beam current. However, EBRF usually use $50 \mathrm{~mA}$ as the upper limit in beam current. Varying the beam current changes the absorbed dose in a linear fashion, allowing for experimentation at doses from 0 to $800 \mathrm{krads}$. The electron beam is scanned at $200 \mathrm{~Hz}$ to give a coverage of 48 " wide and 2" high.

Influent streams at the ERBF are presented to the scanned beam in a falling stream approximately $48^{\prime \prime}$ wide and at the design flow of $120 \mathrm{gpm}$ are 0.15 " thick. Since the maximum penetration in water is approximately 0.29 " for $1.5 \mathrm{MeV}$ electrons, some electrons pass through the stream and thus not all of the beam energy is transferred to the water. With the addition of over-scanning the waste stream to insure that the edges of the stream are irradiated more energy is lost with the result that the efficiency of energy transfer is approximately $60-85 \%$. Thus when the electron beam is operating of $50 \mathrm{~mA}$ $(74 \mathrm{~kW})$ the waste stream is receiving an average dose of approximately $650 \mathrm{krads}$. Total power consumption, including pumps, chillers and other auxiliary equipment is about 120 $\mathrm{kW}$.

Because the system is being used for research and water quality is one of the main experimental variables, three influent streams are directly connected to the facility. These three influent streams are potable water, chlorinated secondary wastewater and secondary an aerobically digested sludge that is $2-5 \%$ in solids. Batch experiments can be run at the facility utilizing a 6000 gallon truck connected to the influent pump. Experiments have been conducted using raw wastewater collected and transported in the tank trucks.

The EBRF is instrumented with resistance temperature devices (RTDs) to obtain direct estimates of absorbed dose. Five RTDs ( 2 sensors) and effluent ( 3 sensors) stream immediately before and after irradiation. The RTDs are connected via an interface to a computer which continuously reads and records temperatures and the absorbed dose is estimated by converting the observed temperature differences to the energy transferred to the water.

During experiments to determine the removal efficiency of parent compounds and to collect samples to determine reaction by-products, samples are taken prior to and after irradiation. These samples are obtained in the control room from continuously running sample streams. ${ }^{1}$

A schematic of the facility is shown in Figure 2 . 


\section{U.S. EPA Superfund Innovative Technology Evaluation (SITE) Program}

The Superfund Amendments and Reauthorization Act (SARA) of 1986 mandates that EPA select, to the maximum extent practicable, remedial actions at Superfund sites that create a permanent solution (as opposed to land-based disposal) for contamination that effects human health and the environment. In doing so, EPA is directed to use alternative or resource recovery technologies. In response, EPA's Office of Research and Development (ORD) and the Office of Solid Waste and Emergency Response (OSWER) established the following three programs to maks up the SITE program:

- a program to accelerate the use of new or innovative technologies to clean Superfund sites through field demonstration

- a program to foster further research and development of treatment technologies that are at the laboratory or pilot scale

- a program to demonstrate and evaluate new or innovative measurement and monitoring

The primary purpose of the SITE program is to enhance the development and demonstration and, thereby, establish the commercial availability of innovative technologies applicable to Superfund sites. The SITE program has encouraged the development and implementation of innovative treatment technologies. The SITE program is administered by the ORD's Risk Reduction Engineering Laboratory, based in Cincinnati, Ohio.

The SITE program includes the following programs:

- emerging technology

- demonstration

- monitor and measure technology

- technology transfe $i$

\section{SITE demonstration program}

The purpose of the SITE demonstration program is to demonstrate the innovative technology in hazardous-waste sites. Data gathered in the field are used to assess technology performance, potential need for preprocesses and/or postprocesses, potential operation problems, and capital and operating costs. The field demonstration will enable engineers to evaluate the technology's applicability for a specific hazardous-waste site.

\section{SITE emerging technology program}

The emerging SITE technology program provides technical and financial support to vendors for bench (lab) and pilot-scale testing of innovative technologies. Once an innovative technology is proven at the conceptual stage, it will become an emerging technology program.

The SITE program has established the following goals:

- identify and remove impediments to the development and commercial use of alternative technologies

- demonstrate promising innovative technologies to establish reliable performance and cost information for site characterization and remediation decisions

- develop procedures and policies that encourage the selection of alternative treatment remedies at Superfund sites

- develop a program that promotes and supports emerging technologies 
In September 1992, the perox-pure chemical oxidation technology, developed by the Peroxidation Systems, Inc., was evaluated under the SITE program at Lawrence Livermore National Laboratory (LLNL), Site 300 . LLNL is a DOE complex located in Tracy, California.

During the four-week demonstration, about 400,000 gallons of groundwater contaminated with VOCs was treated.

\section{EPA SITE Emerging Technology Demonstration of Electron Beam Technology}

Several experiments with electron beam irradiation of aqueous streams were conducted. These experiments had as their focus the effect of water quality, solute concentration, and irradiation dose on removal efficiency for TCE and PCE. To develop a more quantitative understanding of the factors that affect the removal efficiency of TCE and PCE from water by electron beam, experiments were designed that included the variables identified as important in the preliminary studies, i.e., total carbonate alkalinity, bicarbonate/carbonate ion speciation, solute concentration, and the presence and absence of clay. The waters used for detailed experiments were potable water and raw secondary wastewaters. Potable water is delivered to the plant with a $\mathrm{pH}$ of approximately 9 and an alkalinity of 45 to $60 \mathrm{mg} \mathrm{L}$ as $\mathrm{CaCo}_{3}$.

To examine the effect of the addition of solids, kaolinite was added to give a concentration of $3 \%$ solids by weight. The addition of kaolinite resulted in a lowering of $\mathrm{pH}$ of the solution to approximately 7 , and therefore only $\mathrm{pH} 7$ and $\mathrm{pH} 5$ could be directly compared for the removal of TCE and PCE in the presence and absence of clay.

In tests to compare the dose required to remove $99 \%$ of the TCE and PCE in three different quality waters at the lower and higher initial solute concentration, it was apparent that the removal of the TCE and PCE required a smaller dose in potable water than in either wastewaters. Although the quality of the three waters was quite different, there was not a large difference (two-fold) in the removal efficiency between the three waters. The removal of PCE required a higher dose than TCE under equivalent conditions. This is consistent with the $\mathrm{OH}$ reaction rate constants of the two compounds.

More detailed studies were conducted at various TCE and PCE concentrations. The presence of suspended solids up to $3 \%$ had no significant effect on the removal of TCE and PCE when compared to solutions that had no clay. Solute concentration did not affect removal efficiency at the two lower concentration studied. However, higher doses were required to achieve the same removal efficiency when the initial solute concentration approached to $1 / 10 \mathrm{mgL} .^{2}$

The removal of benzene and toluene has been evaluated as a function of solute concentration, absorbed dose, $\mathrm{pH}$, and total solids content. The removal efficiency of $99 \%$ for benzene and toluene does not appear to be affected by solution $\mathrm{pH}$. In 
addition, 3\% w/w Kaolin clay did not appear to significantly affect the removal efficiency of either benzene or toluene at pH 7 and 5, compared with the absence of Kaolin under similar experimental conditions. Reaction by-products identified for benzene include phenol, 1,2-1,3,-and 1,4dihydroxy benzene, formaldehyde, acetaldehyde, and glyoxal. The reaction by-products for toluene include, o-cresol, formaldehyde, acetaldehyde, glyoxal, and methylgloxal. In all cases, the sum of the reaction by-products identified, as well as any unreacted solute, accounted for less than $9 \%$ of the total carbon mass balance for benzene and less than $2 \%$ of the total carbon mass balance for toluene at an absorbed dose of 200 $\mathrm{krad}$. Presumably the remaining organic carbon is mineralized to carbon dioxide and water or to as yet unidentified reaction by-products. ${ }^{3}$

\section{Innovative Nature of the Technology}

The most common methods of treating groundwater contaminated with solvents and other organic compounds include air stripping, steam stripping, chemical oxidation, carbon adsorption, and biological treatment. Chemical oxidation technologies destroy organic contaminants rather than transfer them to another medium, such as activated carbon or the ambient air. However, like any technology, chemical oxidation has kinetic limitations, restricting applicability to certain contaminants. As a result of these limitations, conventional chemical oxidation technologies have been slow in becoming a cost-competitive treatment option. ${ }^{4}$

The electron beam technology is a process that is easy to handle. It was demonstrated at the EPA SITE Emerging Technology Division and elevated to the SITE demonstration program for field demonstration.

The use of electron beam technology increases destruction efficiency of organic compounds and does not produce air emissions or generate sludge and spent media that require further processing, handling, or disposal.

\section{Application and Benefits to SRS}

The electron beam technology demonstration at SRS has potential benefit to some groundwater remediation projects at SRS and other DOE facilities. At SRS, organic contaminants are the most commonly found contaminants in groundwater, consequently, this technology has the potential to remove the contaminants from the groundwater effectively. The primary objective is to provide site-specific data to support SRS remediation actions. The secondary objective for the technology demonstration will be to obtain necessary information for a full-scale remediation treatment system. The information will inciude operating and construction costs, removal efficie.ncy, potential operating problems, and process chemical dosages if applied.

Through technology transfer, demonstration results will be shared with EPA remedial project manager, government agencies, remediation consultants/contractors, and research facilities. EPA will publish the demonstration results, which are available to all hazardous and waste management media. In addition, the demonstration performance and results will be shared with other DOE facilities.

Skid-mounted components are assembled on a 48-foot trailer at the manufacturing facility. This treatment unit will be towed to the proposed site location. 
Contaminated groundwater piping will feed into the electron beam trailer-mounted unit. Effluent from this demonstration unit will be directed to an existing air-stripper.

The electron beam demonstration system requirements are:

- power: 460 volts $/ 3$ phase

- pumps: includes influent/effluent pumps

- piping: 3" cam-lock coupling

DOE, EPA, and ER reviewed various potential waste units at SRS. As a result of the review progress of waste sites, $M$ Area was selected as a potential site for electron beam technology demonstration. The proposed site layout is included in Figure 3.

\section{Key Contacts}

Additional information on the electron beam technology can be obtained from the following sources:

\section{U.S. EPA Site Program}

Norma Lewis

Section Chief

EPA SITE Program

26 W. Martin Luther King Drive

Cincinnati, OH 45268

(513) $569-7665$

\section{U.S. DOE}

Allison A. Blackmon

Savannah River Site Environmental Restoration

P. O. Box A

Aiken, SC 29802

(803) 725-9762

\section{WSRC}

Ahmet Suer

Environmental Restoration Engineering

P. O. Box 616

(992-4W)

Aiken, SC 29803

(803) 644-6900, fax (803) 644-6922

\section{Vendor}

William J. Cooper, Ph.D.

High Voltage Environmental Applications, Inc.

9562 Doral Boulevard

Miami, Florida 33178

(305) 593-5330, fax (305) 593-0071 


\section{References}

1. Cooper, W. J., T. D. White, C. N. Kurucz, and M. G. Nickelsen, High Energy Electron Beam Irradiation for Disinfection and the Removal of Hazardous Organic Chemicals from Water, Wastewater, and Sludge: An Overview, January 1991.

2. U. S. Environmental Protection Agency, "Electron Beam Treatment for Removal of Trichloroethylene and Tetrachloroethylene from Streams and Sludge", EPA/540/F-92/009, Emerging Technology Bulletin, Washington, D. C., October 1992.

3. U. S. Environmental Protection Agency, "Electron Beam Treatment for Removal of Benzene and Toulene Aqueous Streams and Sludge", EPA/540/F93/502, Emerging Technology Bulletin, Washington, D.C., October 1992.

4. Nickelsen, M. G. and W. J. Cooper, "Removal of Benzene and Selected AlkySubstituted Benzenes from Aqueous Solutions Utilizing Continuous HighEnergy Electron Irradiation", Environmental Science \& Technology, Vol. 92, 1992. 


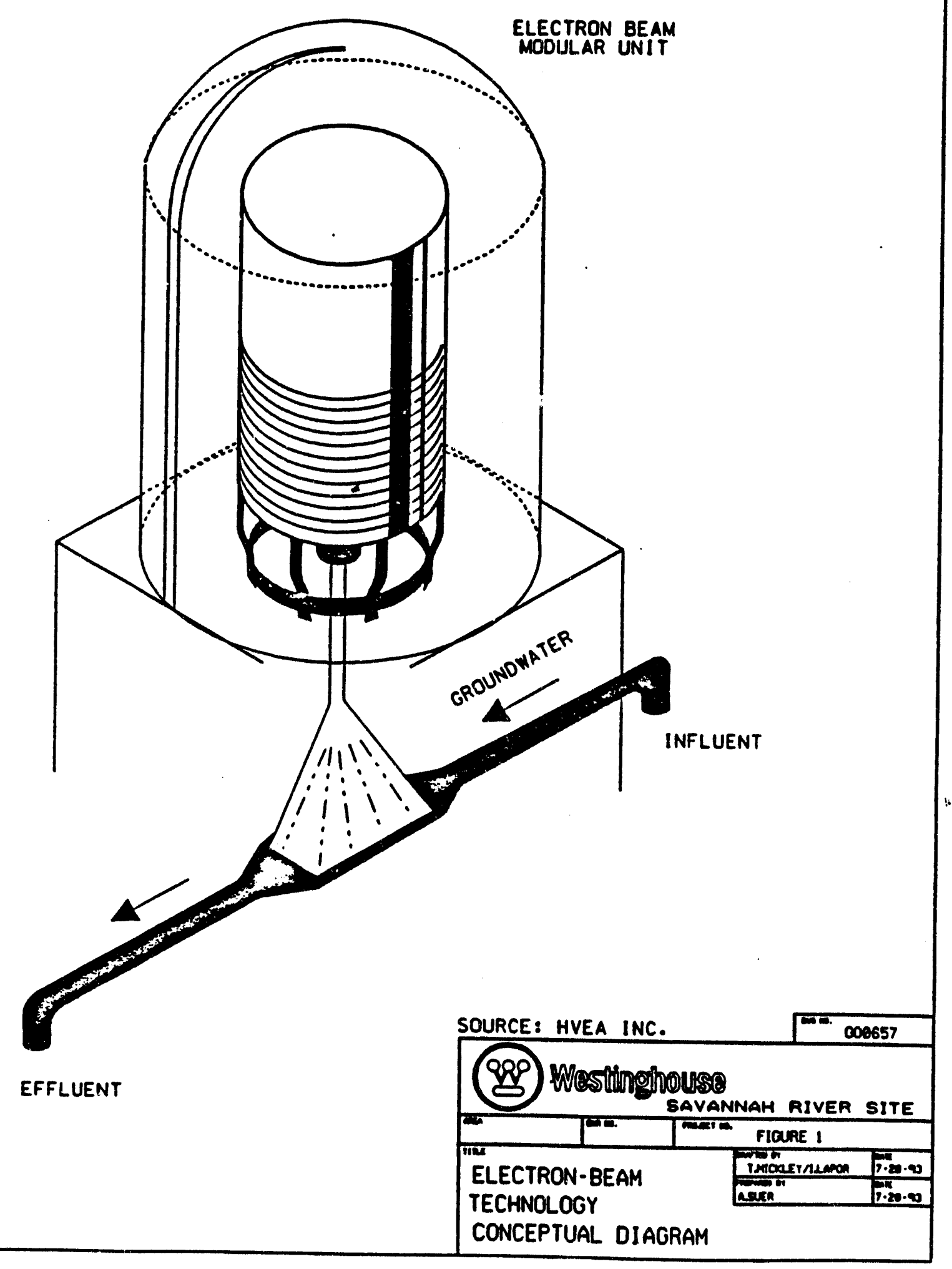




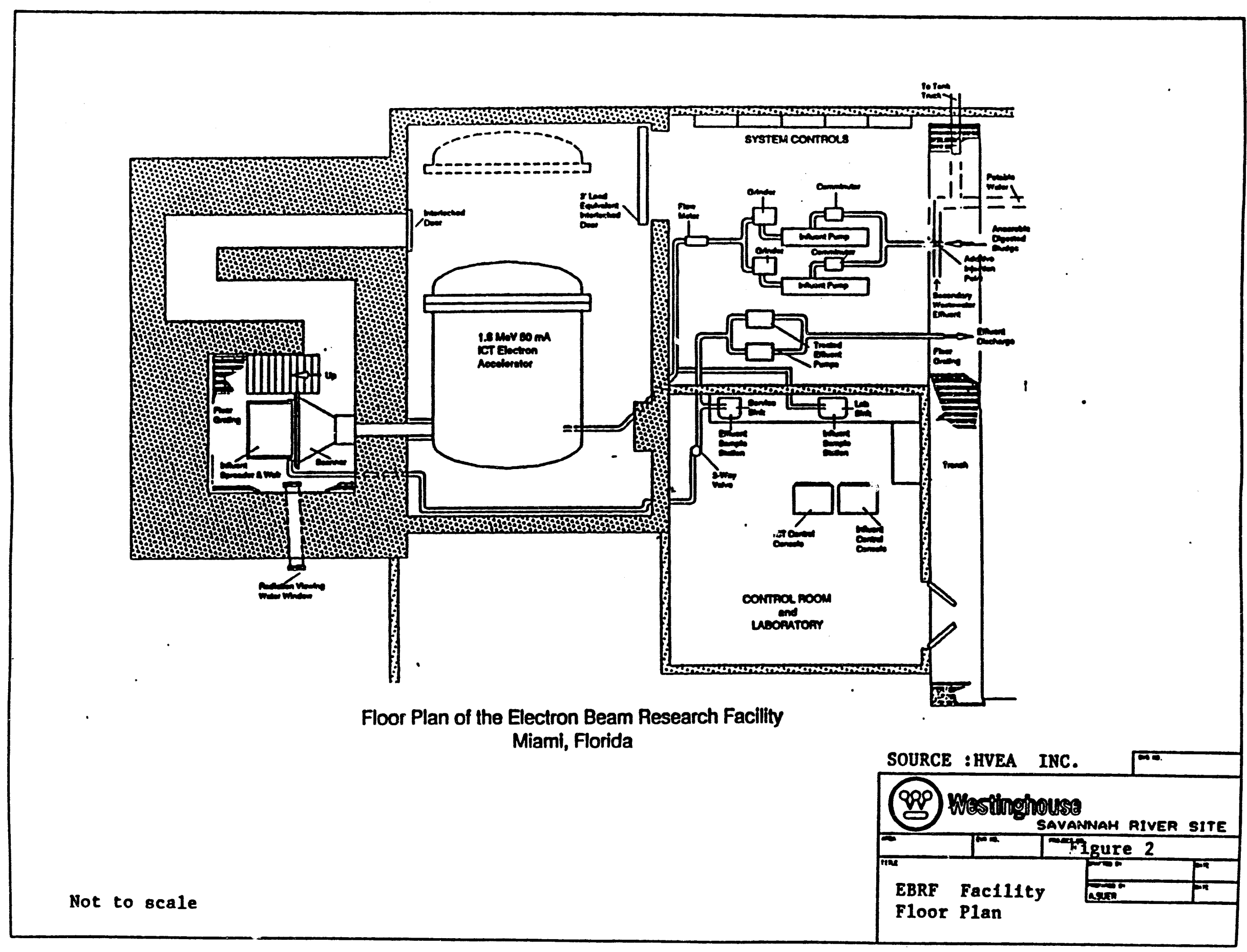




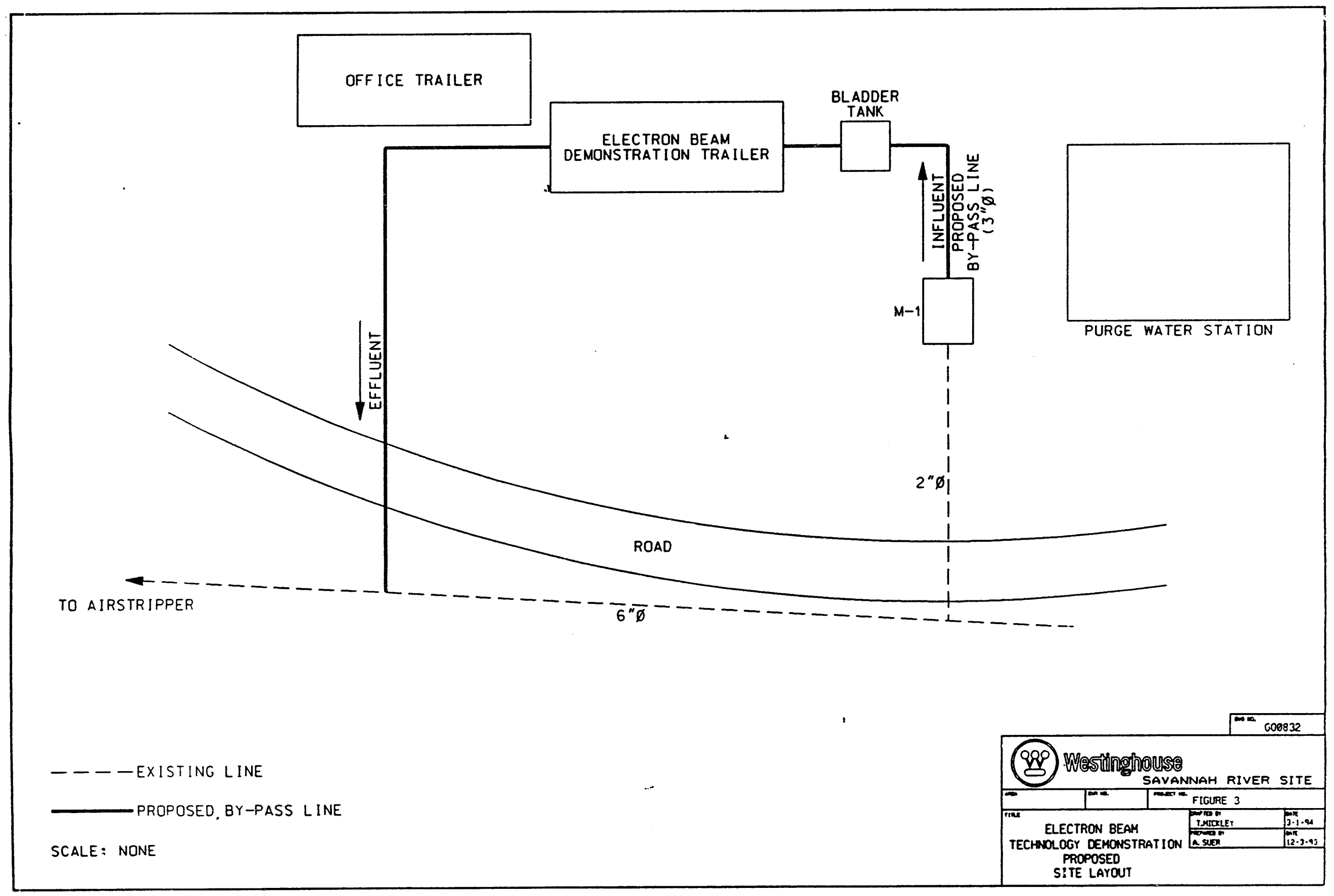



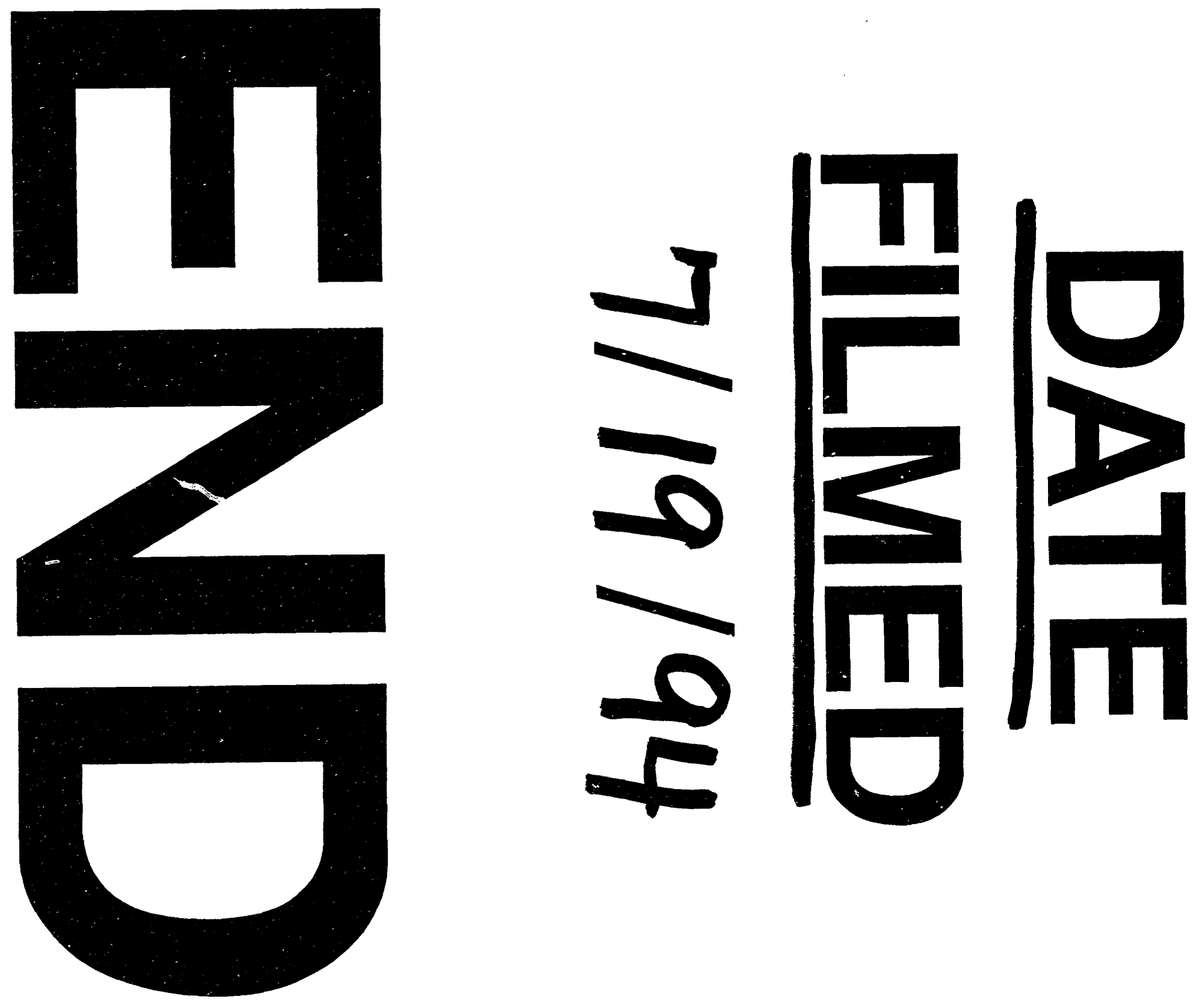
